\title{
O Triste Quadro da Saúde: Análise de um Out-Door
}

\section{The Sad Picture of Health: Analysis of a Billboard}

\section{Fernando Lefèvre ${ }^{1}$}

LEFÈVRE, F. The Sad Picture of Health: Analysis of a Billboard. Cad. Saúde Públ., Rio de Janeiro, 11 (3): 506-510, Jul/Sep, 1995.

This article analyzes a billboard entitled "The Sad Picture of Health", displayed in the city of São Paulo in May 1993. Based on various internal features and considering the surrounding social context, the billboard allows for two radically different interpretations. In the case of a such a "signed" billboard, such ambiguity implies a bad choice of the message intended to be conveyed by the sponsors. The author thus suggests that sponsors of such public announcements be aware of the ambiguity of their messages and forms of discourse.

Key words: Discourse Analysis; Role of Physicians; Government; Health

\section{INTRODUÇÃO}

Na cidade de São Paulo começa a circular, pelos idos de abril/maio de 1993, um out-door intitulado "O triste quadro da saúde".

Antes de entrar na análise do produto convém assinalar, como manda a análise do discurso (Pecheux apud Carmo, 1993) em grandes linhas, as condições externas de produção do discurso, ou seja, neste caso, o contexto político, institucional e ideológico que envolve o surgimento do referido out-door.

\section{CONDIÇÕES EXTERNAS DE PRODUÇÃO DO DISCURSO}

No momento em que o out-door circulou caracteriza-se uma crise conjuntural a estrutural de caráter político-institucional: governo federal cumprindo mandato tampão, com baixa credibilidade em relação à opinião pública e desempenho técnico sofrível; volta de episódios de corrupção; crise na saúde com baixíssimo nível de eficiência do sistema público de assistência médica; ofensiva ideológica de base privatista e neoliberal; greves no sistema público estadual de São Paulo, submetido à vio-

\footnotetext{
'Departamento de Práticas de Saúde Pública, Faculdade de Saúde Pública, Universidade de São Paulo, Av. Dr. Arnaldo, 715, São Paulo, SP, 01246-904, Brasil.
}

lenta compressão salarial; corporação médica com sua credibilidade afetada diante da opinião pública e, finalmente, perspectiva da próxima revisão constitucional, com possibilidades de alteração na legislação constitucional referente à Saúde.

Os ingredientes deste contexto, cremos, fornecem algumas informações de caráter externo (ao out-door) necessárias para a interpretação do seu significado.

\section{DESCRIÇÃO DO OUT-DOOR}

Formalmente, out-door é composto por uma superfície rigorosamente dividida ao meio:

I. metade esquerda (de quem olha para o outdoor) constituída por fundo negro a letras brancas com as quais se escreve:

a.(na parte de cima desta metade) a mensagem-título do cartaz : O Triste Quadro da Saúde;

b. (em letras menores, na parte de baixo desta metade) a "assinatura" dos autores da mensagem, ou seja, nesta ordem:

- Sindicato dos Médicos de São Paulo;

- Federação Nacional dos Médicos;

- Associação Médica do IAMSPE;

- Associação Médica Brasileira. 
II. Metade direita constituída por foto em branco e preto apresentando mulher pobre, de meia idade, deitada em cama ou leito de hospital improvisado num local claramente identificável como um corredor de hospital.

III. Entre as duas metades, na parte superior do cartaz, mensagem, em letras vermelhas, enquadrada por uma tarja vermelha superior e uma inferior: "O Governo é o Responsável".

\section{ANÁLISE DO OUT-DOOR}

\section{Característica Genérica 1: a "Tristeza"}

Sob o título:" O Triste Quadro da Saúde" o out-door pode ser descrito por uma característica geral que salta imediatamente aos olhos do observador: ele é confeccionado em "branco e preto" (é a sua, em termos lingüísticos e semióticos, "oposição" imediata e globalmente mais visível) com a finalidade, óbvia, de sugerir, conotativamente a idéia de "tristeza": como nos ensina a semiótica, as cores e a ausência de cores (Todorof et al., 1977) têm sido, deste tempos imemoriais, usadas como recursos significativos, obedeçam elas ou não a definições ou codificações mais ou menos fechadas. No caso presente, um dos significados mais óbvios da oposição: cores/ausência de cores é o sentido correspondente de alegria/tristeza, ou seja, a alegria é "colorida" e a tristeza "branca e preta".

Assim, já que "o quadro da saúde é triste", é quase obrigatória a escolha do "branco e preto" para a "tonalidade" do out-door.

\section{Característica Genérica 2: a Autoprova e o Completamento}

Outra característica genérica deste out-door é que, como grande parte dos out-doors, ele "funciona" por meio de um mecanismo de "autoprova da sua verdade"; isto é, a foto, enquanto interpretante icônico (Pierce, 1974) é a "prova" da verdade do enunciado verbal; ou melhor, na ordem em que deve ser lido o, cartaz, a afirmação, à esquerda: "o triste quadro da saúde" é "provada" pela foto, à direita, que mostra e comprova a "realidade" (visto tratar-se de foto) do "triste quadro da saúde": o cartaz deve ser lido da esquerda para a direita porque uma "prova" não deve, visual ou perceptualmente, vir "antes" (isto é, à esquerda do campo de visão) da afirmação que se quer "provar".

Acrescente-se, ademais, que as duas partes, além de manterem entre si uma relação de "prova", se complementam e se integram, sem redundância ou repetição (como acontece com muitos cartazes), porque a afirmação da esquerda ("o triste quadro da saúde") necessita de um completamento já que, empírica e objetivamente, não é uma afirmação propriamente dita, mas mais uma legenda da foto. É claro, contudo, que, a despeito de não ser, aparentemente, uma afirmação, há, sem dúvida, uma intenção afirmativa. Devemos, com efeito, imaginar que, embutida na mensagem verbal explícita, esteja uma afirmação implícita (Ducrot, 1972) do tipo: "Nós, os médicos signatários, estamos afirmando que a saúde, hoje, pode ser vista ou entendida como configurando um triste quadro".

Em resumo podemos dizer que a esquerda e a direita do cartaz relacionam-se, com vistas ao seu "fechamento", de dois modos:

1. Afirmação verbal $\longleftrightarrow$ prova icônico-fotográfica;

2. Foto $\longleftrightarrow$ legenda.

\section{A "Assinatura” dos Médicos}

Passemos agora para a análise da segunda parte da primeira metade da mensagem, isto é, o nome das associações médicas. Nossa hipótese a respeito do sentido desta parte do out-door é que se trata aí da manifestação da presença dos sujeitos autores da afirmação e signatários da mensagem. Isto é, são os médicos que estão afirmando "que a saúde é ou configura um triste quadro". Esta hipótese se reforça quando acrescentamos à análise a outra mensagem verbal do out-door, ou seja, "o responsável é o governo". Com efeito, na interpretação da mensagem : "o responsável é o governo" parece imprescindível admitir a presença dos médicos como sujeitos, configurando, no total, a seguinte mensagem reconstruída:

"Nós, médicos signatários, estamos afirmando que a saúde, hoje, pode ser vista 
como conformando um triste quadro, do qual o abandono dos pacientes em camas improvisadas nos corredores dos hospitais, como demonstra a foto, é uma flagrante ilustração. Mas nós, médicos signatários, estamos igualmente e sobretudo colocando que a responsabilidade por isso, ou seja. por aquele paciente que você está vendo abandonado num corredor, não cabe aos médicos e sim ao governo".

Ou, em uma formulação sintética: "Nós, médicos, estamos colocando que a saúde configura um triste quadro e que a responsabilidade por isso é do governo.

De uma maneira geral parece impor-se uma interpretação da mensagem total do cartaz em termos de uma campanha de defesa da corporação médica, à medida que esta possa estar sendo, de algum modo, responsabilizada, por parte da sociedade em geral, pelo descalabro da saúde.

Nessa linha, podemos imaginar esta interpretação apoiada num discurso do inconsciente da corporação médica que poderíamos enunciar da seguinte forma:

"Antes que você, cidadão, possa imaginar que nós, médicos, possamos ter algo a ver com o descalabro da saúde - que você está vendo todo dia pelo noticiário da mídia estamos colocando que a culpa

(responsabilidade) é do governo. Tanto nós, médicos, temos certeza de que a

"responsabilidade é do governo" que estamos, pública e corajosamente, colocando a imagem e a realidade de um paciente abandonado num corredor de hospital; imagem que, em si mesma, poderia sugerir, por se tratar de abandono de paciente, que a culpa ou responsabilidade fosse do médico, posto que socialmente é ele o grande responsável pelos pacientes “.

Podemos colocar, portanto, como marca desta presença do inconsciente, a idéia de "culpa", que aparece no discurso de modo atenuado e disfarçado através do seu sinônimo "responsabilidade".

\section{De que "Governo" se Trata?}

Restaria analisar o segmento "do governo" da mensagem: "a responsabilidade é do governo".

Lançando mão do conceito de escolha paradigmática (Eco, 1973), diríamos que a escolha por "do governo", além de poder ser entendida como "não do médico", deve também ser entendida como fazendo parte do conjunto de opções possíveis, dada pelas condições externas ao discurso, de caráter político-conjuntural, composto por:

- "do Governo Estadual"

- "do Governo Municipal" ou "da Prefeitura"

- "do Governo Federal"

- "do Fleury"

- "do Itamar"

- "do Maluf"

- "do SUS"

Sem entrar numa análise - necessariamente subjetiva - sobre o porquê da escolha de "do governo" - haveria várias razões concretas para esta escolha como, por exemplo, a de, para efeitos jurídicos, não identificar, concretamente, nenhum responsável - temos que admitir que ela, na prática, confere ao leitor ou consumidor da mensagem a possibilidade de interpretar "do governo" como "de todos os governos" ou seja "do Estado" ou "do Público" e, por via de conseqüência "não do Privado".

É claro que essa interpretações não podem ser deduzidas diretamente da mensagem nem das intenções conscientes dos signatários, mas a ambigüidade do discurso e o contexto geral descrito no início permitem este tipo de leitura.

\section{A Foto ou a Realidade do Triste Quadro do Abandono}

Quanto à foto, podemos colocar que cumpre bem o seu papel, pois, além de "retratar" (pelo branco e preto) a "tristeza" do quadro da saúde, pelo seu conteúdo iconográfico, conota fortemente a idéia de "abandono" não apenas porque o paciente encontra-se jogado num conredor do hospital, mas também porque este, na qualidade 
de pessoa humana, aparece quase como um mendigo (a foto, sem dúvida, evoca imagens arquetípicas ou "chaplinianas" de mendigo): com efeito, pela foto o leitor sabe apenas que o ser humano retratado é uma mulher pela saia, já que o rosto é tal forma "abandonado" e indiferente que poderia ser tanto de um homem quanto de uma mulher, pobres e de meia idade.

\section{CONCLUSÃO}

De maneira quase totalmente descritiva e objetiva podemos dizer que o out-door em tela passa, na sua globalidade, a seguinte mensagem:

\section{Eis o triste "retrato em branco e preto" da saúde: pacientes reduzidos à indigência, abandonados num leito de hospital improvisado no corredor. \\ Quem é o responsável por isso? \\ Resposta: o governo.}

Assinado: os médicos.

Digamos que esta é a base objetiva da mensagem que possibilita e permite que se exerça, sobre ela, por parte do leitor, uma ação interpretativa ou decodificadora.

Nesta interpretação, o receptor recorrerá aos seus filtros interpretativos próprios e ao contexto social, político, institucional, ideológico vigente no momento, que opera, através do indivíduo estando este, no mais das vezes, inconsciente destas pressões sociais (Bourdieu, 1990), que ele internalizou -, uma filtragem social da mensagem.

Em conclusão, o que se pode dizer é que um out-door como o que estamos analisando permite, no momento em que ele está sendo divulgado (abril/maio de 1993), entre outras, as duas leituras seguintes:

1. O retrato da saúde é triste, com o abandono dos pacientes e o culpado disso não é o médico, mas o governo que, com sua política salarial para os profissionais de saúde, é o responsável por esta situação. Há que, portanto, valorizar o Sistema Público de Saúde, remunerando melhor os profissionais médicos, para que eles possam atender a população com dignidade.
2. O retrato da saúde é triste, com o abandono dos pacientes, e o responsável por isso não é o médico, mas o Governo, isto é, o Estado ou, mais precisamente o Sistema Público de Assistência à Saúde, que por ser público é, intrinsecamente, ineficiente e incompetente, levando por conseguinte à situação de abandono dos pacientes, impedindo que os profissionais médicos possam exercer livremente o sua missão curativa.

Poderíamos estar nos perguntando, então, com qual das duas interpretações, ideologicamente opostas (ainda que, em função da ambigüidade do texto, perfeitamente possíveis), estavam, isolada ou conjuntamente, comprometidas as instituições signatárias?

Mas, a rigor não nos interessa a resposta, qualquer que seja ela (Cardoso-Filho, 1993). Com efeito, análise objetiva (tanto quanto possível) de textos ou discursos, justamente porque nela não se busca "descobrir" qualquer significado mas tão somente descrever um dado material discursivo atestado, e, com base nesta descrição, avançar algumas hipóteses sobre as descodificações possíveis, aponta para uma importante conseqüência da produção de discursos, como é o caso deste, com destinação pública: neles, o que importa não é o que se pretendeu dizer, mas o que foi efetivamente dito, que não coincide, necessariamente, com a intenção consciente dos emissores; e o que foi efetivamente dito é aquilo que foi processado pelo leitor, com base no material a ele oferecido, considerando as demais condições externas de produção dos discursos.

E o que foi objetivamente oferecido para ser processado pelo leitor revela, a nosso ver de modo incontestável, uma mensagem ambígua. O produto semântico oferecido para ser consumido pelo leitor é, justamente, a ambigüidade, ou seja; no caso, um discurso que tanto pode ser entendido como "politicamente correto" por um leitor "de esquerda" quanto por um leitor de direita".

Porque optou-se, talvez de modo inconsciente, pela ambigüidade? Talvez porque se trate, no fundo, de uma mensagem oriunda não de uma facção política, mas de 
uma corporação profissional - a dos médicos. E no afã de agradar a todos os médicos, agrada-se, igualmente, aos médicos "de esquerda" e aos "de direita".

\section{RESUMO}

\section{LEFÈVRE, F. O Triste Quadro da Saúde:}

Análise de um Out-Door. Cad. Saúde Públ., Rio de Janeiro, 11 (3): 506-510, jul/set, 1995.

Procura-se, neste trabalho, analisar um outdoor presente na cidade de São Paulo, no mês de maio de 1993, e que intitula-se : "O triste quadro da saúde". Em função de vários elementos encontrados no texto e em função do contexto externo, o referido out-door permite e possibilita, pelo menos, duas leituras de sentidos absolutamente opostos, o que, certamente, implica, no caso de um out-door "assinado", uma escolha inadequada da mensagem por parte dos signatários. Em função disso, sugere-se cuidado e atenção para a ambigüidade presente, com muita freqüência, nas mensagens e nos discursos.

Palavras-Chave: Análise de Discurso; Papel do Médico; Governo; Saúde

\section{REFERÊNCIAS BIBLIOGRÁFICAS}

BOURDIEU, P., 1990. Coisas Ditas. São Paulo: Brasiliense.

CARMO, S. I. S., 1993. Luz e sombra nos editoriais da Folha de São Paulo. Perspectivas, S. Paulo, 16: 256-263.

CARDOSO-FILHO, M., 1993. Greve no Governo. Folha de São Paulo, 21 de maio.

DUCROT, O., 1972. Dire et ne Pas Dire. Paris: Hermann.

ECO, U., 1973. O Signo. Lisboa: Presença.

PÊCHEUX, M., 1990. O Discurso: Estrutura ou Acontecimento. Campinas: Pontes.

PIERCE, C. S., 1974. La Ciencia de la Semiótica. Buenos Aires: Nueva Vision.

TODOROF, T.; FONAGY, I. \& COHEN, J., 1977. Linguagem e Motivação: uma Perspectiva Semiológica. Porto Alegre: Globo. 